\title{
Zeolite-based catalysts for the removal of trace olefins from aromatic streams
}

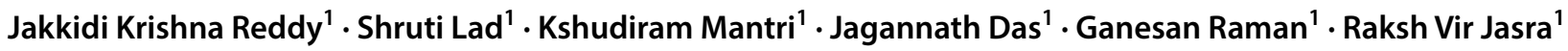

Received: 21 May 2020 / Accepted: 28 July 2020 / Published online: 5 August 2020

(c) The Author(s) 2020

\section{Abstract}

Removal of trace olefins from aromatic liquids was investigated on UZM-8 and MCM-22, which are the family of MWW zeolites. Both these zeolites were synthesized with similar $\mathrm{Si} / \mathrm{Al}$ ratio and characterized by various techniques such as XRD, SEM, ICP, $\mathrm{N}_{2}$ adsorption, Ammonia TPD and solid-state MAS-NMR. Olefin conversion activity over UZM-8 was found to be significantly higher than that of MCM-22. In addition to this, deactivation of UZM-8 was slower than the MCM-22. UZM-8 with irregular stacking of MWW layers possess high external surface area and exposes more number of active sites to the reactant molecules. Mesopores generated due to the disordered layers of UZM-8 allows the fast diffusion of the substrate molecules in which pore clogging does not occur, thus making it more active and slow deactivation than that of MCM-22.

\section{Graphic abstract}

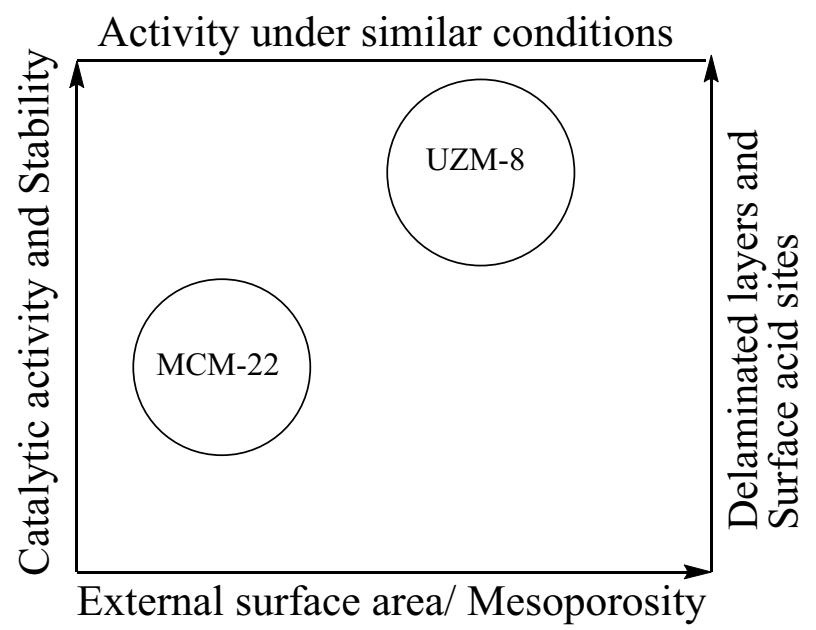

Keywords UZM-8 $\cdot$ MCM-22 $\cdot$ Olefin removal process and Structure activity correlationship

\section{Introduction}

Jakkidi Krishna Reddy

Jakkidi.reddy@ril.com

1 Reliance Technolgy Group, Reliance Industries Ltd., Vadodara Manufacturing Division, Vadodra, Gujarat 391346, India
In petroleum processing, aromatic streams which are used in various petrochemical processes are derived from naphtha reforming and thermal cracking. However, the aromatic streams derived from naphtha reforming and thermal cracking contains undesirable olefinic contaminants which will result into adverse effect on the post reformate hydrocarbon processes [1-3]. Olefinic material can affect the performance 
of downstream equipment, adsorbents and catalysts such as $p$-xylene recovery, xylene isomerization and disproportionation units. These impurities have tendency to oligomerize and form gums and other undesirable by-products which can foul heat transfer surfaces and reduce the efficiency of costly equipment and adsorbents/catalysts. Therefore, the hydrocarbon contaminants must be removed before subsequent processing of the aromatic streams. These detrimental trace olefins can be effectively removed via the acid-catalyzed alkylation of specific aromatics [4-6]. Conventionally, aromatics are refined by acid activated clays and zeolites-based catalysts in industrial plants. However, commercial clays have disadvantages such as poor regeneration performance, and rapid deactivation and environmental impacts due to solid disposal and land filling. Therefore, it is imperative to improve the process for purification of aromatics by developing easily synthesizable, stable and recyclable catalysts.

Olefins removal is a process of alkylation that occurs generally on the surface of clay or zeolite. Among the various zeolites reported in literature, MWW zeolites are found to be more suitable for alkylation reactions [7]. MCM-22 was the first $[8,9]$ invented MWW zeolite that contains two independent pore systems: one consists of two-dimensional sinusoidal 10-ring channels, and the other large 12-ring supercages connected by 10-ring windows. Furthermore, its external surface consists of 12-ring cups. Because the acid sites in those pockets are accessible to large organic molecules, MCM-22 has shown to be applicable to a wide variety of chemical reactions [10-12].

Recently UOP researchers have reported a new layered zeolite named as UZM-8 [13, 14]. UZM-8 is a delaminated MWW-type zeolite has a large number of 12-ring pockets exposed on the crystal surface. Based on its superior physico-chemical properties it is believed that it could be a potentially useful catalyst for the bulkier aromatic hydrocarbon transformations on the surface. In the present investigation, we have studied the olefins removal ability of UZM- 8 and compared its performance with that MCM-22. A structure activity correlationship of both UZM- 8 and MCM-22 is discussed in this report.

\section{Experimental}

\section{Preparation of UZM-8 zeolite}

UZM-8 was synthesized by modification of synthesis recipe as per the reported literature [13]. The reagents employed in this study included diethyl dimethylammonium hydroxide (DEDMAOH, 20\% aqueous solution, Aldrich), Aluminum tri secondary butoxide ( $\mathrm{Al}(\mathrm{Osec}-$ $\mathrm{Bu})_{3}, 97 \%$, Aldrich) and tetra ethyl ortho silicate (TEOS, 98\%, Aldrich). Typical procedure followed for UZM-8 zeolite synthesis was as described below. Predetermined amounts of $\mathrm{Al}(\mathrm{Osec}-\mathrm{Bu})_{3}$ was mixed with DEDMAOH under vigorous stirring. In the next step TEOS and deionized water were added slowly, and the mixture was homogenized by vigorous stirring and aged for overnight to allow the complete hydrolysis and mixing. The solution was then concentrated with a rotary evaporator to remove alcohols formed. To this aluminosilicate gel solution, required quantity of $\mathrm{NaCl}$ solution was added while stirring. The final composition of the synthesis mixture was: 50 $\mathrm{SiO}_{2}: 1 \mathrm{Al}_{2} \mathrm{O}_{3}: 1.77 \mathrm{Na}_{2} \mathrm{O}: 1312 \mathrm{H}_{2} \mathrm{O}: 33$ DEDMAOH. The above solution was transferred into Teflon lined autoclave and subjected to hydrothermal crystallization at $423 \mathrm{~K}$ for 7 days while stirring at 100 RPM. The solid product was collected by centrifugation, washed with deionized water and dried overnight in an oven at $393 \mathrm{~K}$ followed by calcination at $823 \mathrm{~K}$ for $10 \mathrm{~h}$.

\section{Preparation of MCM-22 zeolite}

MCM-22 was synthesized as reported in the literature [15]. The reagents employed in this study included hexamethylene imine (HMI, 99\% purity, Aldrich), Sodium aluminate (55\% $\mathrm{Al}_{2} \mathrm{O}_{3}$ and $45 \% \mathrm{Na}_{2} \mathrm{O}$, Aldrich) and Precipitated silica (95\% pure, Gujarat Multigas). Sodium hydroxide ( $\mathrm{NaOH}, 98 \%$, Sd fine chemicals).

Predetermined amounts of sodium aluminate, sodium hydroxide and denoised water were mixed and stirred until a clear solution is formed. Subsequently hexamethylene imine (HMI) was added to the above solution, followed by the addition of precipitated silica. The final composition of the synthesis mixture was: $45 \mathrm{SiO}_{2}: 1 \mathrm{Al}_{2} \mathrm{O}_{3}: 3.38 \mathrm{Na}_{2} \mathrm{O}: 811.76$ $\mathrm{H}_{2} \mathrm{O}: 10.13$ SDA. The gel was treated hydrothermally at $443 \mathrm{~K}$ for $48 \mathrm{~h}$ in an autoclave under continuous stirring. After the crystallization process, the solid product was separated and washed thoroughly with water till free from alkali. Finally, the material was oven dried at $393 \mathrm{~K}$ followed by calcination at $823 \mathrm{~K}$ for $10 \mathrm{~h}$ under air.

\section{Preparation of $\mathrm{H}$-form zeolites}

Before subjecting the samples for ion exchange the occluded organic materials in the pores of the synthesized zeolites were removed by heating at $823 \mathrm{~K}$ for $10 \mathrm{~h}$ in flowing air under atmospheric pressure. The zeolites were then converted into the $\mathrm{NH}_{4}^{+}$form by exchange in an aqueous $\mathrm{NH}_{4} \mathrm{Cl}$ solution at $353 \mathrm{~K}$ for $3 \mathrm{~h}$. The same procedure repeated for three times till the complete ion exchange occurs. Samples after ion exchange were washed with deionized water and calcined at $823 \mathrm{~K}$ under air to convert $\mathrm{NH}_{4}^{+}$form to $\mathrm{H}$-form zeolites. 


\section{Preparation of extrudates from zeolite powder}

Zeolite powders were shaped in the form of $1.5 \mathrm{~mm}$ cylindrical extrudates using alumina as a binder. In both the cases of UZM-8 and MCM-22 extrudates, zeolite to binder ratio is maintained as 70:30. Formed extrudates were oven dried and calcined in air at $823 \mathrm{~K}$ for $6 \mathrm{~h}$.

\section{Characterization}

Characterization techniques used to elucidate the textural and structural properties of the prepared zeolite materials were XRD, ICP, $\mathrm{N}_{2}$ adsorption, ${ }^{29} \mathrm{Si}$ and ${ }^{27} \mathrm{Al}$ MAS NMR, Ammonia TPD, SEM and TGA. XRD patterns were collected on the Bruker D8 Advance powder diffractometer using Ni-filtered $\mathrm{Cu} \mathrm{K} \alpha$ radiation source at $40 \mathrm{kV}$ and $20 \mathrm{~mA}$, from $2^{\circ}$ to $50^{\circ}$ with a scan rate of $2^{\circ} / \mathrm{min}$. BET surface area and pore size were measured at $77.2 \mathrm{~K}$ using a Micrometrics 3Flex Surface Characterization Analyser. The samples were degassed at $673 \mathrm{~K}$ to a vacuum of $10^{-3}$ Torr, before analysis. MAS NMR of the calcined samples were measured by Bruker-Advance III-HD. ICP of the synthesized samples were measured by using ICAP-7600 Thermo Fisher instrument. Ammonia TPD was measured for total acidity of the zeolite on Autochem 2920. Scanning electron microscopy (SEM) was performed using Nova Nanosem-650 in high-vacuum mode at low voltage.

\section{Catalytic activity test}

The zeolite extrudates of $1.6 \mathrm{~mm}$ diameter in size were packed into a SS tubular reactor (20 $\mathrm{mm}$ i.d.) in a vertical furnace. Catalyst was activated under air stream by heating at a heating rate of $0.5 \mathrm{~K} / \mathrm{min}$ from room temperature to $823 \mathrm{~K}$ for $5 \mathrm{~h}$. After activation, the catalyst bed temperature was brought down to $453 \mathrm{~K}$. The olefin conversion was carried out in continuous flow mode at 10 bar pressure. Feed stream is known as deheptaniser column bottom (aromatic stream with olefins, Table 2) was fed into the reactor using feed pump. The effluent stream was withdrawn periodically and analyzed by auto-titrator and gas chromatography. Key performance indicators (KPI) such as Bromine Index (BI), benzene and toluene formations, $\mathrm{C}_{8}$ aromatics loss, heavier aromatic $\left(\mathrm{C}_{10}+\right)$ formations, etc. were analyzed.

Bromine Index method (ASTM D-1491) was used to determine the olefin content of aromatic containing hydrocarbon. Specifically, the Bromine Index (BI) is defined as the number of milligrams of bromine consumed by $100 \mathrm{~g}$ of hydrocarbon sample. The number of milligrams of bromine absorbed by $100 \mathrm{~g}$ of a hydrocarbon or a hydrocarbon mixture indicates the percentage of olefinic double bonds present in the hydrocarbon mixture. A measure of the reduction in Bromine Index of the product from the process represents the degree of olefin conversion. Olefins conversion was calculated as follows:

$Y=\frac{\left(\mathrm{BI}_{0}-\mathrm{BI}\right)}{\mathrm{BI}_{0}} \times 100$

$Y=$ percentage of olefins conversion or reduction in Bromine Index, $\mathrm{BI}_{0}=$ Bromine Index of the reactant feed. $\mathrm{BI}=$ Bromine Index of the product stream.

\section{Results and discussion}

\section{Characterization}

As can be seen in Fig. 1, XRD patterns show the characteristic peaks of UZM-8 zeolite, which is in good agreement with those reported in the literature [13, 14]. A sharp X-ray peak observed at $2 \theta=7.2^{\circ}$ in UZM- 8 and MCM- 22 corresponds to the interlayer (100) reflection of MWW layered zeolites. Apart from this, the XRD pattern of UZM- 8 is characterized by a broad peak in the $2 \theta$ range $7.5-10.0^{\circ}$, which indicates the disruption in the vertical alignment, a general characteristic of the irregular stack of MWW monolayers [16, 17].

SEM images (Fig. 2) of as-synthesized UZM-8 and MCM-22 zeolites were observed with a magnification of $100,000 \times$. Both the samples exhibited similar morphology with overlapped plate-like MWW layers with $<20 \mathrm{~nm}$ thickness. However, SEM image of UZM- 8 shows more disordered/misaligned stacking of plate like layers. These partially delaminated and disordered stacking MWW layers of UZM- 8 may offer lots of 12 MR cups and acid sites accessibility by reactant molecule.

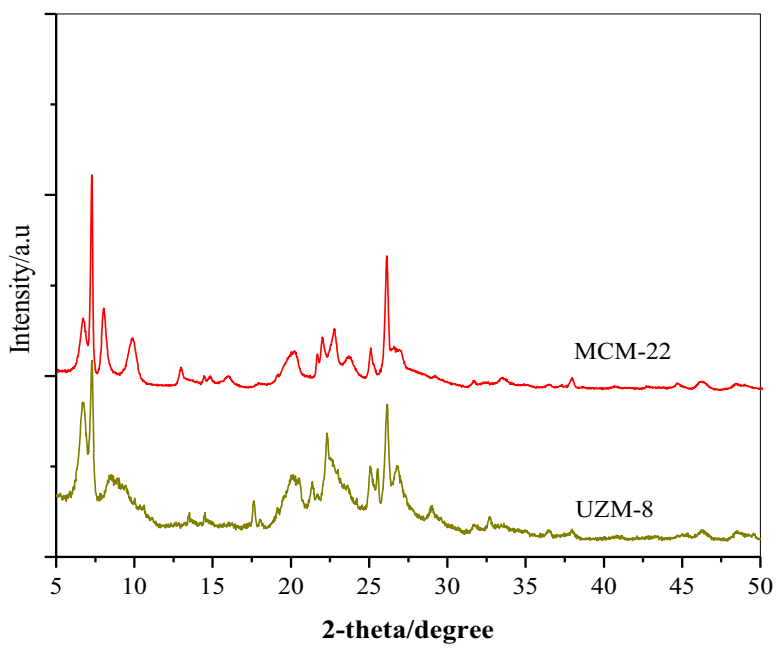

Fig. 1 X-ray diffractograms of as-synthesized UZM-8 and MCM-22

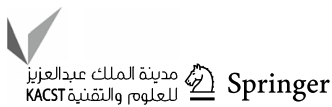




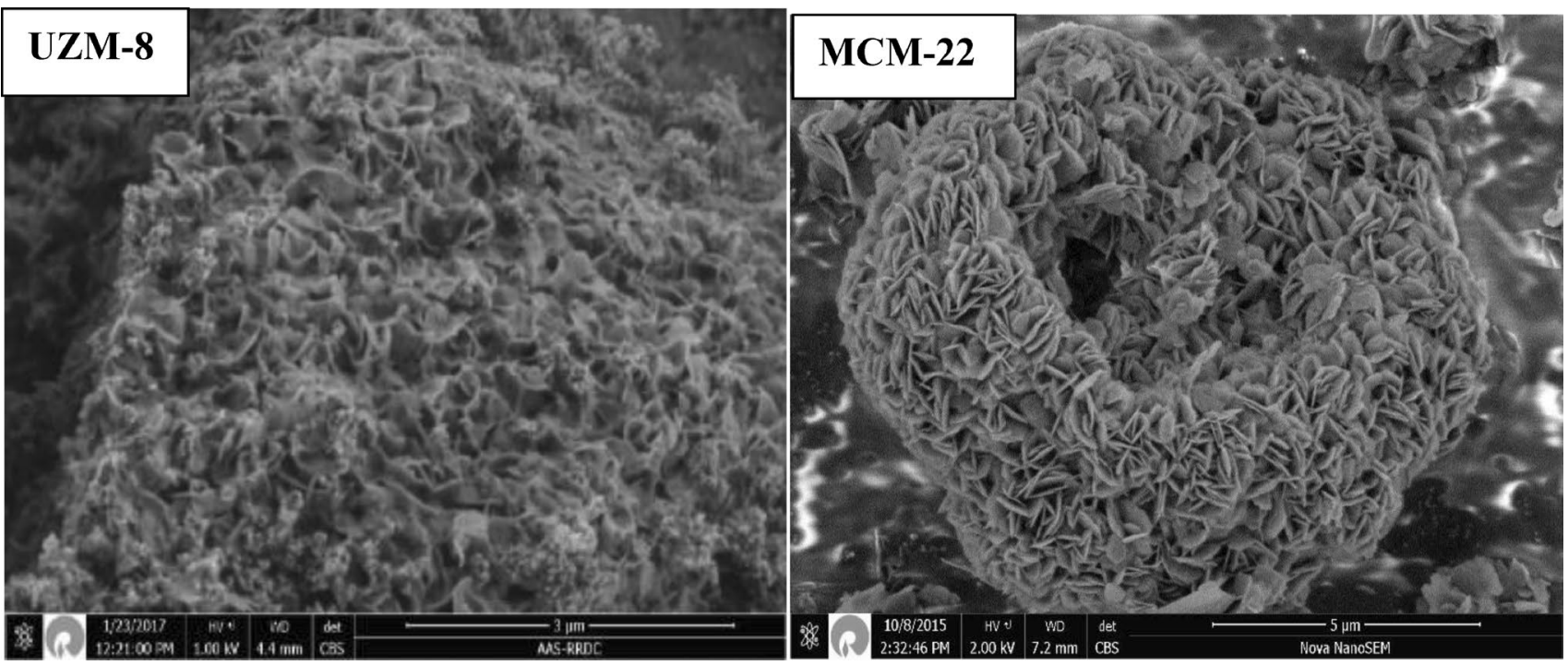

Fig. 2 SEM micrographs of as-synthesized UZM-8 and MCM-22

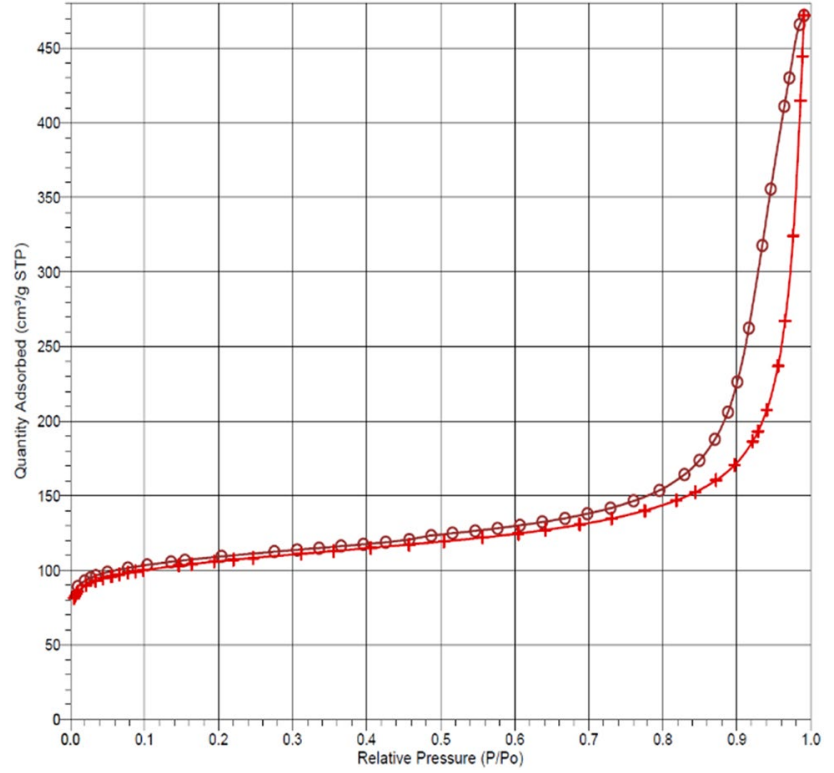

Fig. $3 \mathrm{~N}_{2}$ adsorption-desorption isotherms of calcined UZM-8

Figures 3 and 4 show the $\mathrm{N}_{2}$ adsorption-desorption data for UZM-8 and MCM-22. The total surface area of UZM-8 is higher than that of MCM-22. External surface area of UZM- $8\left(290 \mathrm{~m}^{2} / \mathrm{g}\right)$ is significantly higher than that of MCM$22\left(112 \mathrm{~m}^{2} / \mathrm{g}\right)$ revealing a high degree of stacking disorder of MWW monolayers in UZM-8 (Table 1). MCM-22 exhibits Type I isotherms, typical for microporous zeolites. As shown in Fig. 3, a clear hysteresis loop is observed at high relative pressures in the adsorption isotherms of UZM-8. This indicates the presence of a markedly larger mesoporosity in the UZM-8 zeolite [18]. UZM-8, with high external surface

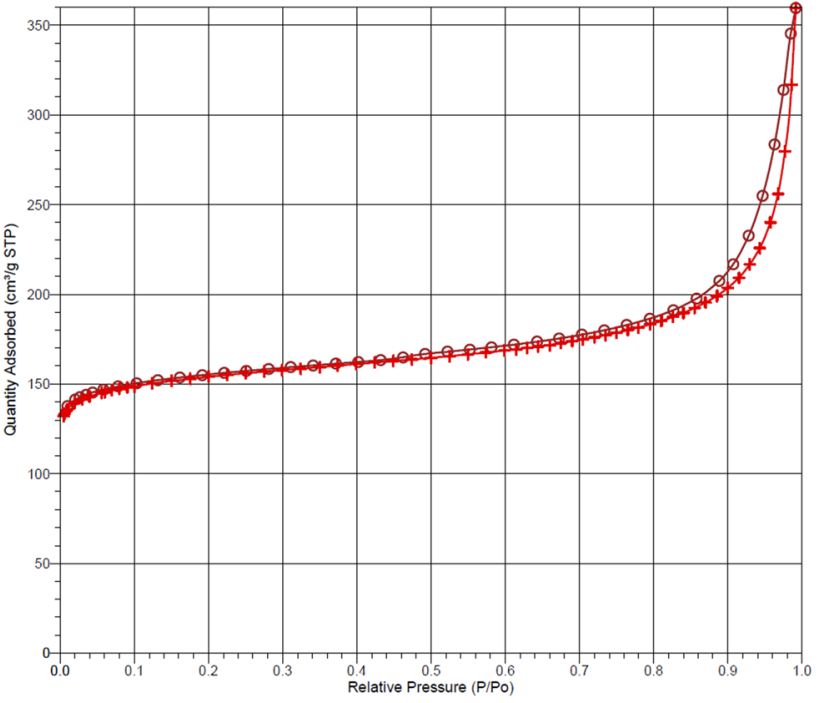

Fig. $4 \mathrm{~N}_{2}$ adsorption-desorption isotherms of calcined MCM-22

area, and mesopore volume may expose more acid sites and minimize the substrate diffusion limitations.

${ }^{29}$ Si MAS NMR and ${ }^{27} \mathrm{Al}$ MAS NMR are the techniques that reveal about the geometry and chemical environment of $\mathrm{Si}$ and $\mathrm{Al}$ in the frame work of the zeolite. Figure 5 shows the ${ }^{29} \mathrm{Si}$ MAS NMR of the UZM-8. The chemical shift in the range of $-110,-115$ and $-119 \mathrm{ppm}$ are attributed to $\mathrm{Si}$ $(0 \mathrm{Al})$ and are denoted as $\mathrm{Q}^{4}$ sites in the spectra. The chemical shift at $-105 \mathrm{ppm}$ corresponds to $\mathrm{Si}(1 \mathrm{Al})$ which are also called as $\mathrm{Q}^{4}$ sites. In addition to this, there was a noticeable ${ }^{29} \mathrm{Si}$ resonances at $-92,-94$ and $-100 \mathrm{ppm}\left(\mathrm{Q}^{3}\right.$ sites $)$, these peaks are attributable to $\mathrm{Si}(\mathrm{OH})$ and $\mathrm{Si}(\mathrm{OH})_{2}$ and $\mathrm{Si}(\mathrm{OH})_{3}$ groups, suggesting that UZM-8 has larger number of surface 
Table 1 Physico-chemical properties of MCM-22 and UZM-8

\begin{tabular}{lllllllll}
\hline Sample & $\mathrm{SiO}_{2} / \mathrm{Al}_{2} \mathrm{O}_{3}{ }^{\mathrm{a}}$ & $S_{\mathrm{BET}}\left(\mathrm{m}^{2} / \mathrm{g}\right)$ & $S_{\text {micro }}\left(\mathrm{m}^{2} / \mathrm{g}\right)$ & $S_{\text {ext }}\left(\mathrm{m}^{2} / \mathrm{g}\right)$ & $V_{\text {total }}\left(\mathrm{cm}^{3} / \mathrm{g}\right)$ & $V_{\text {micro }}\left(\mathrm{cm}^{3} / \mathrm{g}\right)$ & $V_{\text {meso }}\left(\mathrm{cm}^{3} / \mathrm{g}\right)$ & $\begin{array}{l}\text { Total acidity } \\
(\mathrm{mmol} / \mathrm{g} \mathrm{cat})\end{array}$ \\
\hline MCM-22 & 43 & 422 & 310 & 112 & 0.56 & 0.19 & 0.37 & 1.35 \\
$\mathrm{UZM-8}$ & 46 & 490 & 200 & 290 & 0.97 & 0.08 & 0.97 & 1.33 \\
\hline
\end{tabular}

${ }^{\mathrm{a}} \mathrm{SiO}_{2} / \mathrm{Al}_{2} \mathrm{O}_{3}$ data obtained by ICP analysis

${ }^{\mathrm{b}}$ Total acidity estimated by ammonia TPD analysis

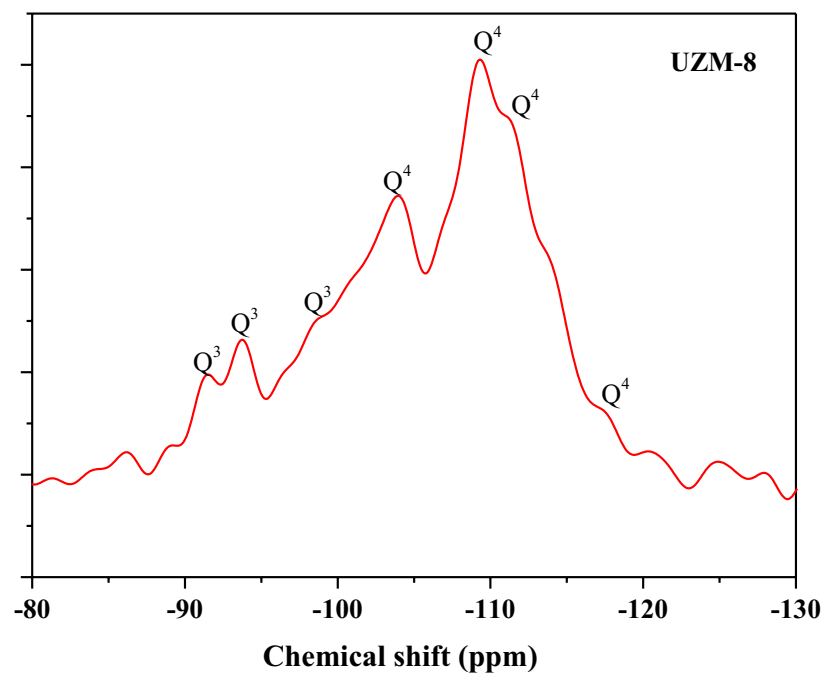

Fig. $5{ }^{29}$ Si MAS NMR of calcined UZM-8

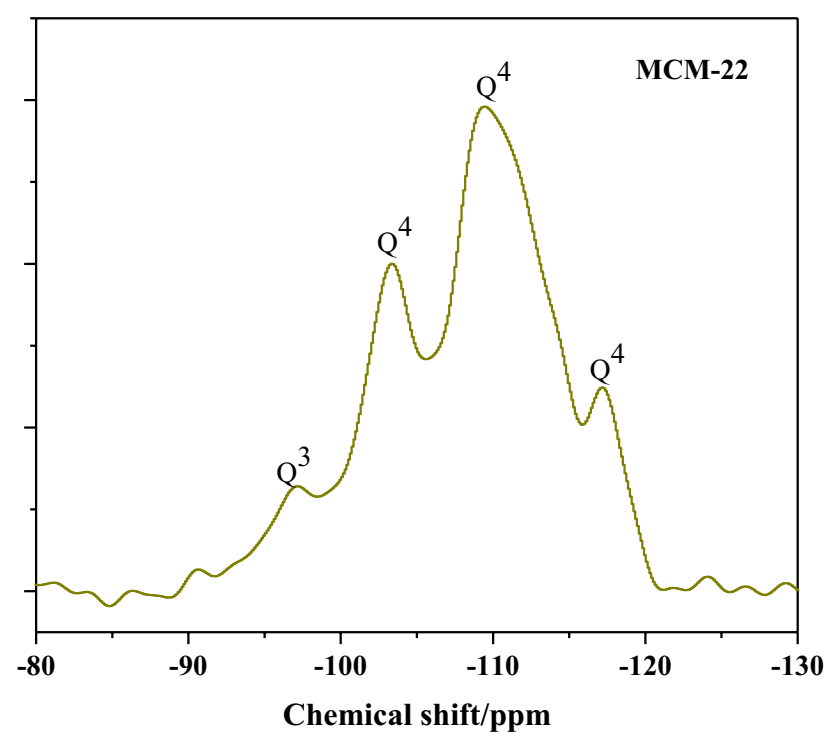

Fig. $6{ }^{29}$ Si MAS NMR of calcined MCM-22

hydroxyl groups, which is also consistent with its high external surface area [18]. As can be seen in Fig. 6, $Q^{4}$ resonances of MCM-22 resembles similar to that of UZM-8, while the

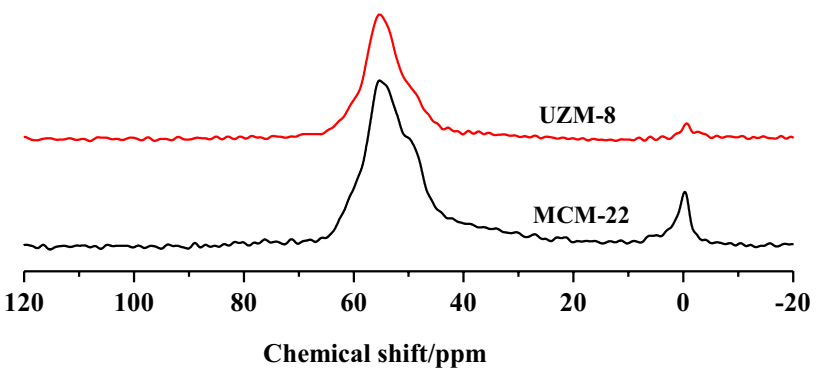

Fig. $7{ }^{27} \mathrm{Al}$ MAS NMR of calcined MCM-22 and UZM-8

number of $\mathrm{Q}^{3}$ resonances are less in MCM-22, this indicates that surface hydroxyl groups in MCM-22 are lesser than in UZM-8.

As shown in Fig. 7, the ${ }^{27} \mathrm{Al}$ MAS NMR spectra of proton form of UZM-8 shows high intense peak at ca. $50 \mathrm{ppm}$, indicating that most of the $\mathrm{Al}$ atoms were tetrahedral coordinated in the zeolite framework. There is also a small peak visible around $0 \mathrm{ppm}$, indicating the presence of small amount of octahedral coordinated aluminum. In contrast the peak at 0 ppm in MCM-22 slightly larger than in UZM-8 indicating high amount of octahedral $\mathrm{Al}$ in MCM-22.

Figure 8 shows the $\mathrm{NH}_{3}$ TPD profiles of UZM- 8 and MCM-22. TPD profile of both the zeolites exhibits two desorption peaks with maxima in the temperature regions of $400-600 \mathrm{~K}$ and $650-800 \mathrm{~K}$. The low temperature $\mathrm{NH}_{3}$ desorption peak attributed to weak acid sites while high temperature desorption peak attributed to strong acid sites. Though the total $\mathrm{NH}_{3}$ desorption peak area in both samples remains same, the relative area ratio of the low-temperature peak to high-temperature peak is slightly higher for UZM-8 than for MCM-22. This may be because, the $\mathrm{NH}_{3}$ molecules adsorbed on the acid sites in the external 12-ring pockets of the MWW structure may be more easily desorbed than those on the acid sites in its sinusoidal 10-ring channels or large 12-ring supercages.

The thermo gravimetric analysis (TGA) of the UZM-8 sample is displayed in Fig. 9. The sample was analyzed in a thermal analyzer from 303 to $1073 \mathrm{~K}$ with a heating rate of $0.5 \mathrm{~K} / \mathrm{min}$ under air flow. The observed weight loss under $403 \mathrm{~K}$ is due to water, and between 403 and $646 \mathrm{~K}$ is probably due to DEDMAOH located in the surface cavities and 


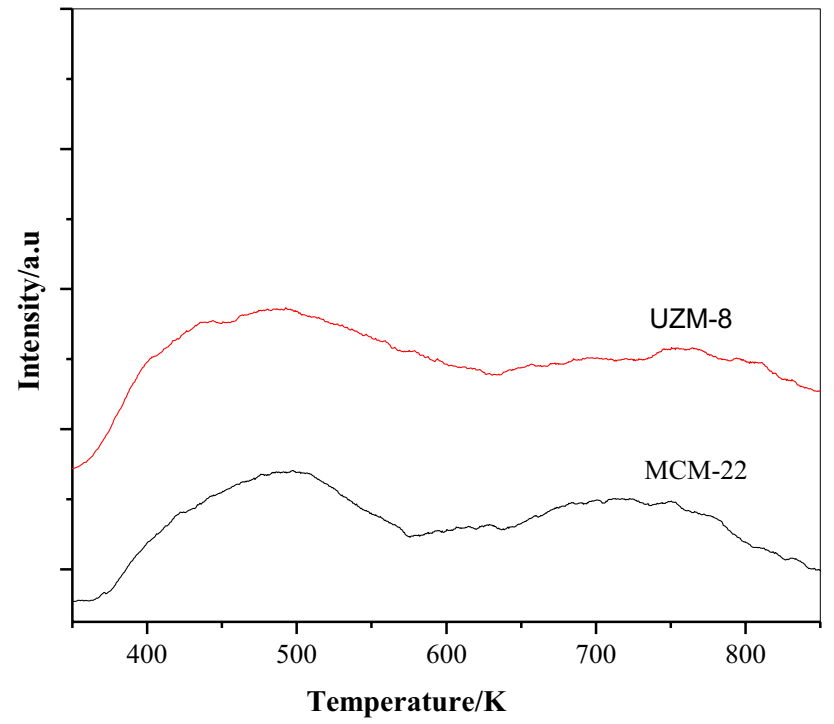

Fig. 8 Ammonia TPD profiles of H-UZM-8 and H-MCM-22

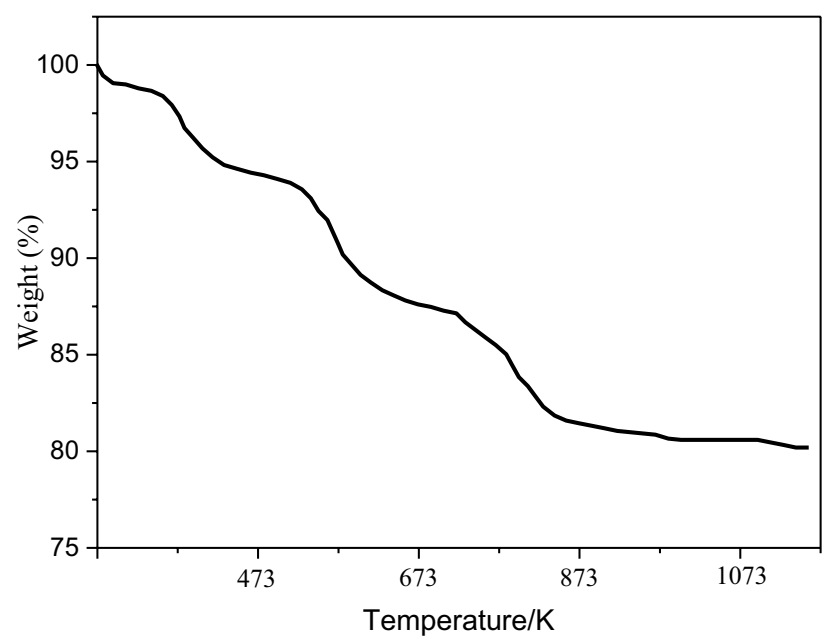

Fig. 9 Thermo gravimetric analysis (TGA) of UZM-8

interlamellar region. Weight loss between 646 and $823 \mathrm{~K}$ may be due to desorption of the residues produced by the fragmentation of template at high temperature.

\section{Catalytic performance}

Catalytic performance of the UZM-8 and MCM-22 was evaluated for the conversion of olefins from a commercial $\mathrm{C}_{8}+$ aromatics stream. It is well known that the alkylation of aromatics with olefins over solid acid catalyst proceeds via the generally accepted carbenium ion mechanism illustrated in Scheme 1. On the basis of this mechanism, the olefin molecules adsorbed on the surface of the zeolite were activated by the Bronsted acid or Lewis acid sites thus resulting in the reduction of double bond to form a carbenium ion. The<smiles>[R]C=C[C@H]1[C@@H](C)[C@H]1[R][C](C)c1ccccc1</smiles><smiles>[R]Cc1ccc(C([R])C)cc1</smiles>

Scheme 1 Alkylation of aromatics by olefins over zeolite surface

Table 2 Component distribution of reactor inlet (feed stream) and out let (product stream)

\begin{tabular}{llll}
\hline $\begin{array}{l}\text { Component dis- } \\
\text { tribution (wt\%) }\end{array}$ & Feed stream & $\begin{array}{l}\text { MCM-22 } \\
\text { Product stream }\end{array}$ & $\begin{array}{l}\text { UZM-8 } \\
\text { Product stream }\end{array}$ \\
\hline Non-aromatics & 1.5 & 1.2 & 1.2 \\
Benzene & 0 & 0 & 0 \\
Toluene & 2.5 & 2.6 & 2.62 \\
Ethyl benzene & 7.4 & 7.1 & 7.2 \\
Para xylene & 8.75 & 8.66 & 8.7 \\
Meta xylene & 20.7 & 20.64 & 20.6 \\
Ortho xylene & 12.31 & 12.3 & 12.4 \\
Total xylenes & 41.76 & 41.6 & 41.7 \\
$\mathrm{C}_{9}+$ aromatics & 46.84 & 47.5 & 47.4 \\
\hline
\end{tabular}

GC data of 6th h time on stream is shown in the table. Reaction conditions: temperature $453 \mathrm{~K}$, pressure $10 \mathrm{bar}$ and $\mathrm{WHSV}=2.1 / \mathrm{h}$

electrophilic attack of the carbenium ion on the aromatic $\pi$-electrons leads to alkylation reaction thus resulting in alky benzenes and polyalkyl benzenes [19, 20].

Composition of the feed employed for the olefin's removal experiments is shown in Table 2. Both the catalysts were tested under same process conditions. As shown in Fig. 10, the initial olefin conversion over UZM-8 was $98 \%$ while on MCM-22 it is $93 \%$. With time on stream studies, olefin conversion activity of UZM- 8 at 12 th $\mathrm{h}$ has dropped to $91 \%$, while on MCM-22 it has dropped to $76 \%$, indicating fast deactivation of MCM-22. It is observed that even at 12th $\mathrm{h}$ TOS, UZM-8 was showing $15 \%$ higher olefin conversion than to MCM-22. The high catalytic performance of UZM- 8 can be explained based on its physico-chemical properties. Ammonia TPD measurements shows that there 


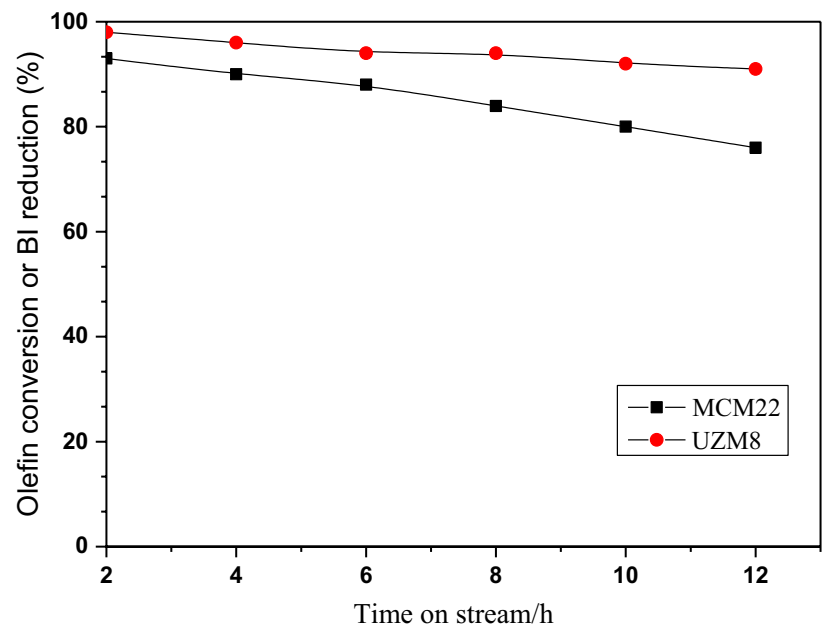

Fig. 10 Comparative olefin removal activity over UZM-8 and MCM22 catalysts. Reaction conditions: temperature $453 \mathrm{~K}$, pressure 10 bar and $\mathrm{WHSV}=2.1 / \mathrm{h}$

is no significant difference in the total acidity (Table 1); however, the difference in the exposure of acid sites might result from their different textural and structural properties. Generally, the more acid sites accessed by reactants, the better the olefin conversion performance. Many publications [7, 21] have claimed that acid sites on 12 MR cups of MWW zeolites were mainly utilized as active centers for catalytic reaction without restriction on diffusion of reactant or product. As UZM-8 is observed with irregular stacking layers with high external surface area $\left(290 \mathrm{~m}^{2} / \mathrm{g}\right)$, exposes more number of acid sites to the olefin molecules thus leading to high conversion of olefins. Mesopores generated due to the disordered layers of UZM-8 allows the fast diffusion of the molecules in which pore clogging does not occur as fast as in MCM-22. Therefore, the rate of deactivation was slow in UZM-8. To investigate the changes in the content of aromatics after reaction, product distribution obtained by the GC analysis is presented in Table 2. Here the chemical reaction is a simple alkylation of aromatics with olefins as a result of which a slight increase in the heavier aromatics $\left(\mathrm{C}_{9}+\right.$ mostly alkylated aromatics $)$ is seen in the treated feed over both the zeolites UZM-8 and MCM-22. The important concern of this process is, as xylenes are more important components of this stream, xylene loss should not occur after the reaction. As seen in Table 2, no significant change in the concentration of xylenes is seen before and after the reaction. Additionally, as feed stream contains bulkier aromatic substrates, alkylation reactions occurs over the surface of the zeolite rather than the pores, therefore we have not seen any undesirable products except alkylbenzenes in the product stream. It is clearly understood that UZM-8 in comparison with MCM-22 has shown a better olefin removal activity without xylene loss. To investigate the activity of

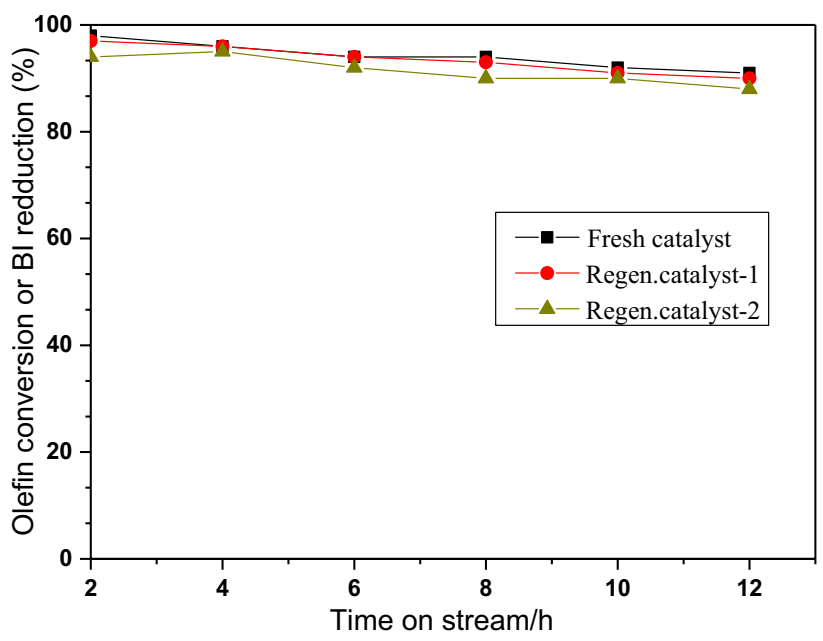

Fig. 11 Comparative olefin removal activity of fresh and regenerated UZM- 8 catalysts. Reaction conditions: temperature $453 \mathrm{~K}$, pressure $10 \mathrm{bar}$ and $\mathrm{WHSV}=2.1 / \mathrm{h}$

regenerated UZM-8 zeolite, spent zeolite catalyst was regenerated and tested for olefin removal activity. From Fig. 11, it is observed that even after 2 cycles of regeneration olefin conversion remains same thus revealing the structure intactness and reusability of UZM-8 zeolite.

\section{Conclusions}

UZM-8 and MCM-22 are the family of MWW layered zeolites synthesized and studied for the removal of trace olefins from aromatic streams. The characterization results of this study reveals that UZM-8 consists of a high degree of stacking disorder of MWW monolayers, giving it a considerable mesoporosity and high external surface area. Because of these specific features, accessibility of acid sites to the substrate molecules is more on the surface, which resulted in high activity of UZM-8. In addition to this, mesopores generated due to the disordered layers of UZM- 8 allows the fast diffusion of the substrate molecules in which pore clogging does not occur, thus making it very slow deactivation than that of MCM-22. These studies suggests that UZM-8 can be a highly effective catalyst for the removal of olefins from the aromatic streams.

Open Access This article is licensed under a Creative Commons Attribution 4.0 International License, which permits use, sharing, adaptation, distribution and reproduction in any medium or format, as long as you give appropriate credit to the original author(s) and the source, provide a link to the Creative Commons licence, and indicate if changes were made. The images or other third party material in this article are included in the article's Creative Commons licence, unless indicated otherwise in a credit line to the material. If material is not included in the article's Creative Commons licence and your intended use is not

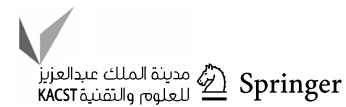


permitted by statutory regulation or exceeds the permitted use, you will need to obtain permission directly from the copyright holder. To view a copy of this licence, visit http://creativecommons.org/licenses/by/4.0/.

\section{References}

1. Brown SH, Chaudhuri TK, Santiesteban JG (2002) Process for BTX purification. US Patent 6500996

2. Brown SH, Helton TE (2010) Regeneration of catalyst used in purification of aromatic streams. US Patent 201002704067A1

3. Pu X, Shi L (2013) Commercial test of the catalyst for removal of trace olefins from aromatics and its mechanism. Catal Today 212:115-119

4. Qing Z, Jianfei L, Jiajia Y, Li S, Xin W (2016) Catalyst for purification of aromatics over a promising $\mathrm{SO}_{4}{ }^{2-} / \mathrm{ZrO}_{2}$. China Pet Process Petrochem Technol 18:49-56

5. Liu N, Pu X, Shi L (2014) Direct synthesis of promising industrial organic-inorganic hybrid silica containing methane sulphonate. Chem Eng Sci 119:114-123

6. Pu X, Liu N, Shi L (2015) Acid properties and catalysis of USY zeolite with different extra-framework aluminum concentration. Microporous Mesoporous Mater 201:17-23

7. Shi Y, Xing E, Xie W, Zhang F, Mu X, Shu X (2019) UZM-8 zeolite synthesized from solid aluminosilicate gel and its catalytic performance. Ind Eng Chem Res 58:7725-7733

8. Leonowicz ME, Lawton JA, Lawton SL, Rubin MK (1994) MCM22: a molecular sieve with two independent multidimensional channel systems. Science 264:1910-1913

9. Kennedy GJ, Lawton SL, Rubin MK (1994) ${ }^{29} \mathrm{Si}$ MAS NMR studies of a high silica form of the novel molecular sieve: MCM-22. J Am Chem Soc 116:11000-11003

10. Kumar N, Lindfors LE (1996) Synthesis, characterization and application of H-MCM-22, Ga-MCM-22 and Zn-MCM-22 zeolite catalysts in the aromatization of n-butane. Appl Catal A 147:175-187

11. Corma A, Triguero JM (1997) The use of MCM-22 as a cracking zeolitic additive for FCC. J Catal 165:102-120
12. Verhoef MJ, Creyghton EJ, Peters JA, Bekkum HV (1997) Reductive etherification of substituted cyclohexanones with secondary alcohols catalysed by zeolite H-MCM-22. Chem Commun 20:1989-1990

13. Rhode LM, Lewis GJ, Miller MA, Moscoso JG, Gisselquist JL, Patton RL, Wilson ST, Jan DY (2004) Crystalline aluminosilicate zeolitic composition: UZM-8. US patent, 6756030

14. Jan DY, Miller RM, Koljack MP, Bauer JE, Bogdan PL, Lewis GJ, Gajda GJ, Koster SC, Gatter MG, Moscoso JG (2006) Hydrocarbon conversion process using catalysts comprising UZM-8 and UZM-8HS compositions. US Patent 7091390

15. Lai WF, Kay RE (2010) MCM-22 family molecular sieve composition. US Patent 7846418B2

16. Roth WJ, Dorset DL (2011) Expanded view of zeolite structures and their variability based on layered nature of 3-D frameworks. Microporous Mesoporous Mater 142:32-36

17. Gopalakrishnan GJ, Lobo RF (2000) Characterization and catalytic properties of MCM-56 and MCM-22 zeolites. Microporous Mesoporous Mater 40:9-23

18. Hyeok CS, Lee J, Shin J, Hong SB (2015) Zeolite UZM-8: synthesis, characterization, and catalytic properties in isopropylation of benzene with 2-propanol. Top Catal 58:537-544

19. Martens JA, Jacobs PA (2001) Introduction to acid catalysis with zeolites in hydrocarbon reactions. Stud Surf Sci Catal 137:633-671

20. Pu X, Liu NW, Jiang ZH, Shi L (2012) Acidic and catalytic properties of modified clay for removing trace olefin from aromatics and its industrial test. Ind Eng Chem Res 51:13891-13896

21. Shi Y, Xing E, Xie W, Zhang F, Mu X, Shu X (2015) Sizecontrolled synthesis of MCM-49 zeolites and their application in liquid-phase alkylation of benzene with ethylene. RSC Adv 5:13420-13429

Publisher's Note Springer Nature remains neutral with regard to jurisdictional claims in published maps and institutional affiliations. 